\title{
ФЕМТОСКАН, 3D-БИОПЕЧАТЬ, НАНОХИРУРГИЯ И БИОЧИПЫ: В ПРЕДДВЕРИИ НАУЧНОГО И ТЕХНОЛОГИЧЕСКОГО ПРОРЫВА
}

\section{FEMTOSCAN, 3D BIOPRINTING, NANOSURGERY AND BIOCHIPS: THRESHOLD OF SCIENTIFIC AND TECHNOLOGICAL BREAKTHROUGH}

И.В.Яминский, д.ф.-м.н., проф. МГУ имени М.В. Ломоносова, генерапьный директор Центра перспективных технологий, (ORCID: 0000-0001-8731-3947) / yaminsky@nanoscopy.ru

I.V.Yaminsky, Doctor of Sc. (Physics and Mathematics), Prof. of Lomonosov Moscow State University, Director of Advanced Technologies Center, (ORCID: 0000-0001-8731-3947)

DOI: 10.22184/1993-8578.2019.12.5.240.245

Получено: 23.08.2019г.

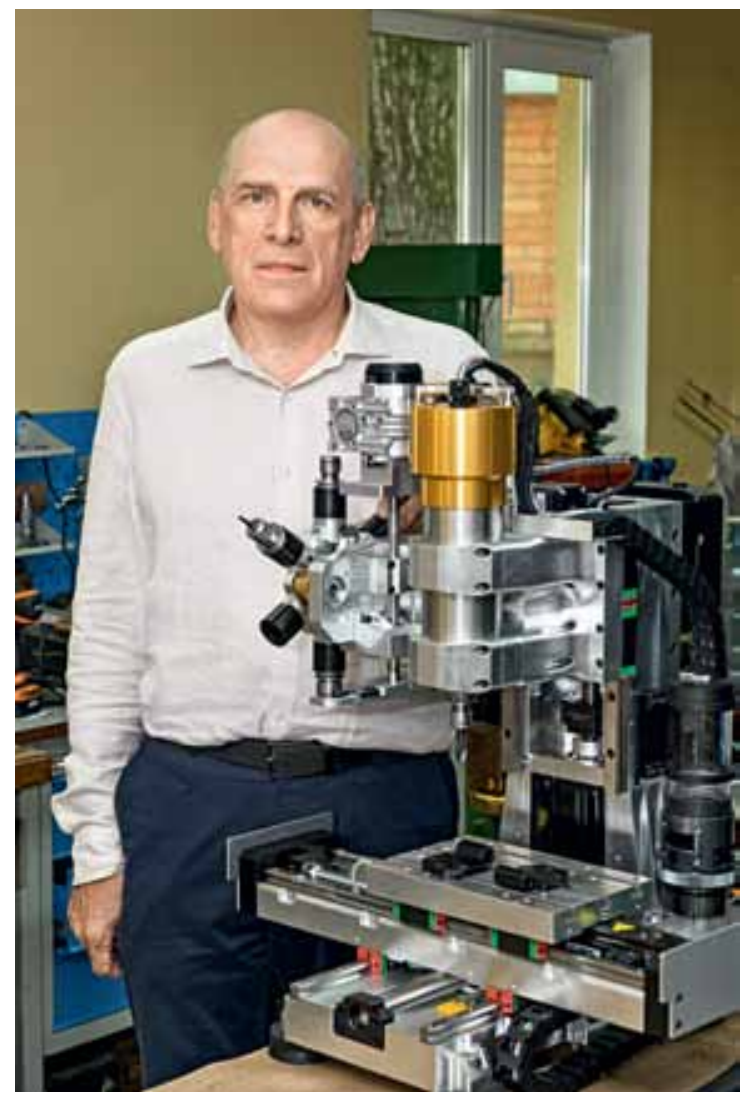

Смена технологических укладов ознаменовалась переходом к нанотехнологическому уровню исследования веществ, в том числе и биологической материи, развитием технологий строительства на уровне биомакромолекул, созданием интеллектуальных биочипов и инструментов для нанохирургии, прецизионной обработки материалов с нанометровой точностью. Сканирующая зондовая микроскопия в совокупности с родственными методами превратила изучение тайн жизни в увлекательные исследования, закладывающие основы грядущего научного и технологического прорыва. Своими мыслями, идеями и историей развития цифровой наноскопии делится доктор физико-математических наук, профессор МГУ имени М.В.Ломоносова, генеральный директор Центра перспективных технологий Игорь Владимирович Яминский.

The change in technological paradigms was marked by a transition to the nanotechnological level of substance research, including biological, the development of construction technologies at the biomacromolecular level, the creation of intelligent biochips and tools for nanosurgery and precision processing of materials within submicron accuracy. The scanning probe microscopy, together with related methods, has turned the study of the life secrets into an exciting research that lays the foundation for the upcoming scientific and technological breakthrough. Doctor of Physics and Mathematics, Professor of Lomonosov Moscow State University, Director of Advanced Technologies Center Igor Vladimirovich Yaminsky shares his thoughts, ideas and history of the digital nanoscopy development. 
С чего начинались ваши исследования и как вы пришли к созданию Центра перспективных технологий?

Все зарождалось в далеком теперь 1985 году, когда я защитил кандидатскую диссертацию на кафедре физики колебаний физического факультета МГУ. Возглавлял ее членкорреспондент Российской академии наук Мигулин Владимир Васильевич, который завел традицию проводить по пятницам научные семинары. На одном из таких семинаров я услышал доклад молодого доктора наук Лихарева Константина Константиновича о микроскопе с металлическим зондом. Этот микроскоп позволял наблюдать атомы и молекулы вещества, над которыми зонд перемещался в туннельном контакте. Эта тема захватила меня, и с конца 1985 года я начал попытки собрать туннельный микроскоп. Важная работа, как мне тогда казалось, состояла в том, чтобы создать устройство, "блоху", которая, перемещаясь, могла бы с точностью до десятков нанометров осуществлять начальное сближение зонда с поверхностью образца. Однако, благодаря сотрудничеству с научной группой доктора физико-математических наук Панова Владимира Ивановича, которая впервые в России к тому времени создала сканирующий туннельный микроскоп, эта идея была умело переработана. К концу 1987 года был создан практически полностью цифровой микроскоп "Скан-7". С его помощью мы обнаружили на поверхности образца меди (111) регулярные возвышения и поняли, что увидели атомы. После этого наши исследования и разработки стали развиваться с удивительной быстротой благодаря необычайно творческой и профессиональной команде Панова В.И. - Савинову Сергею, Моисееву Юрию, Васильеву Сергею, которая преодолевала любые трудности и создала всего за два месяца прототип первого цифрового туннельного микроскопа. Работая на кафедре квантовой электроники Леонида Вениаминовича Келдыша, мы в эпоху перестройки за короткое время создали 35 микроскопов, которые стали работать в институтах, университетах и компаниях, в том числе и за границей, в Германии. Василий Леонов написал тогда программное обеспечение для туннельного микроскопа, и мы получили возможность получать и обрабатывать изображения в цифровом виде. Вскоре мы совместили этот комплекс с атомно-силовым микроскопом, получив новый, уникальный прибор для научных исследований. С тех пор мы развивали и улучшали его, добавляли новые режимы работы, например, магнитносиловую микроскопию, электростатическую микроскопию, режим силы трения, резонанс ные моды. В нашу последнюю разработку, "ФемтоСкан X", мы недавно интегрировали режим капиллярной микроскопии для изучения биологической материи, живых клеток в нативном состоянии, в их развитии и движении. Фундаментальные пределы, достигае мые при помощи зондового микроскопа, находятся на уровне фемто - $10^{-15} \mathrm{M}, 10^{-15} \Phi, 10^{-15} \mathrm{~A}$, $10^{-15} \mathrm{H}$ - великолепном наборе возможностей для исследований наномира. Сканирующая зондовая микроскопия применяется в физике, химии, биологии, медицине и позволяет узнать, как устроены белки, где расположены их реакционные группы, изучить работу ферментов, увидеть, как создаются комплексы гистонов и ДНК, и как образуются хромосомы. Один из наших проектов, поддержан ный Российским фондом фундаментальных исследований, был связан с исследованием самого начального этапа возникновения широко распространенного вирусного заболевания - гриппа. Оно начинается, когда вирус гриппа А проходит через мембрану эпителиальной клетки. Визуализация и наблюдение выявили молекулярные механизмы инфицирования, показали, какие рецепторы в них участвуют, как сиаловые кислоты взаимодействуют с гемагглютинином вируса, как оболочка вируса сливается с клеточной стенкой и впрыскивает в клетку восемь молекул РНК. Так начинается инфицирование.

Сканирующий зондовый микроскоп стал информативным инструментом для изучения самой сложной материи во Вселенной биологической, причем ее изучение можно проводить in vivo и in vitro. Мы наблюдали структуру нейронов, сейчас вплотную приближаемся к изучению нейронных сетей и механизма прохождения нервных импульсов. Одним из интереснейших применений зондовой микроскопии является молекулярное конструирование. Представьте 3D молекулярный принтер, в котором в качестве форсунки используется стеклянный нанокапилляр с диаметром выходного отверстия от 1 до 100 нм. Он позволяет печатать биомакромолекулами трехмерные конструкции. А если на кончик 
нанокапилляра прикрепить белок альфагемолизин, то можно проводить секвенирование ДНК с помощью закона Ома. Когда нуклеотид ДНК проходит через канал альфа-гемолизина, меняется электрическое сопротивление канала. По изменению сопротивления можно точно определить последовательность нуклеотидов в цепи ДНК. При этом можно прочитать молекулы ДНК длиной 10 мкм и более. С помощью многоканальных нанокапилляров можно также вводить в клетку белки, ДНК и другие химические вещества. Таким образом можно не только диагностировать влияние веществ на клетку, но и реализовывать трехмерную молекулярную печать.

Появились и другие новые методики исследований. Так, совмещение ядерного магнитного резонанса и атомно-силовой микроскопии позволяет идентифицировать различные изотопы атомов и определять химический состав вещества, в том числе и биологических макромолекул, с разрешением на уровне отдельных атомов.

Если продолжить разговор о биологической материи, то сейчас вы изучаете процессы, протекаюие при инфицировании ее вирусами, а в перспективе просматривается ли возможность исследований, связанных с лечением заболеваний?

Наилучший способ борьбы с вирусным заболеванием - это его предотвращение. Именно этому посвящены наши работы в области сенсорных технологий молекулярной диагностики. Преимуществом нашего метода является высокая чувствительность: способность обнаруживать вирусы при их чрезвычайно низкой концентрации в жидкостях. Для решения этих задач мы стали создавать биосенсоры, основанные на принципе атомносиловой микроскопии. Механизм работы биосенсора следующий: если на кантилевер попадает вирус, то изменяется резонансная частота его колебаний. Это можно определить с помощью прецизионной электроники зондового микроскопа. Чувствительность системы позволяет зафиксировать даже одну вирусную частицу. Для этого метода не нужны метки и дополнительные реагенты.

Этим проектом заинтересовалась фирма LG Electronics, поскольку биосенсор получается компактным, мобильным и недорогим устройством. Кроме того, биосенсоры можно размещать в кондиционерах, системах очистки воды, стиральных машинах. В течение трех лет проекта нами были продемонстрированы уникальные возможности биосенсоров.

Не менее важным для нас был проект с POCHАНО по разработке нанотехнологического оборудования для материаловедения, биологии и медицины. Мы создали полностью цифровое производство зондовых микроскопов и кантилеверных биосенсоров. Это была полезная для нас школа в плане понимания разработки стратегии бизнеса, юридического сопровождения, оформления результатов. От полукустарного производства мы шагнули к полностью современному промышленному высокотехнологичному производству. В этом году мы поставили 14 микроскопов в Кванториумы таких научных центров, как город Королев и Сколково. Наше оборудование - это не только научные приборы, но и инструменты, с помощью которых можно проводить обучение школьников и студентов. Используя основные режимы работы наших микроскопов, школьники могут получать изображения белков, бактерий, вирусов, РНК, ДНК, клеток, измерять размеры атомов, проводить литографию и рисовать нанокартинки на поверхности графита и других материалов.

Как вы организовали взаимодействие с МГУ и другими образовательными организациями? МГУ имени М.В.Ломоносова - это ведущий образовательный и научный центр, где работает очень много чрезвычайно квалифицированных и умных людей. Работа в МГУ дает нам возможность устанавливать творческое общение с учеными и получать самую квалифицированную помощь по многим вопросам. МГУ это мощный источник молодых, мотивированных, профессиональных, пытливых умов, быстро углубляющихся в тематику новых разработок. Любая растущая компания мечтает о таких сотрудниках, а мы их получаем напрямую, привлекая студентов к научной работе еще на младших курсах. Многие наши молодые сотрудники идут в аспирантуру, так, Ахметова Ассель недавно стала аспиранткой на факультете биоинженерии и биоинформатики и занимается вопросом обнаружения бактерий и вирусов при сверхнизких концентрациях. У нее уже более 50-ти научных работ. Главным разработчиком программного 
обеспечения "ФемтоСкан Онлайн" стал наш студент, впоследствии аспирант и ведущий программист Александр Филонов. Его карьерный путь - яркий пример профессионального роста специалиста и преимущества выработанной нами системы, когда обучение и исследовательская деятельность проводится в МГУ, а научно-производственная работа параллельно осуществляется в инновационной компании.

Кроме научного поиска, на какие практические разработки вы хотели бы обратить внимание наших читателей?

Мы всегда были нацелены на получение практических результатов. Несколько лет назад мы обратили внимание на фрезерногравировальные станки. В современной механообработке, как и в зондовой микроскопии, требуются очень точные перемещения и контроль силового воздействия на образец. На сегодняшний день требования к точности в механообработке перешагнули микронный уровень и перешли в нанометровый диапазон. Электроискровые станки способны позиционировать и обрабатывать изделия с точностью до единиц нанометров. Во фрезерных станках важно учитывать усилия при механической обработке, поэтому обеспечение точности позиционирования инструмента - весьма нетривиальная задача. Миниатюризация научного оборудования и технологические потребности в точности делают наши разработки востребованными в самых разных областях при решении научных и практических задач. Для другого типа обработки, используя фемтосекундный лазер, можно обеспечить нанометровую точность при изготовлении биосенсоров и устройств микрофлюидики.

Планируются ли исследования, связанные с диагностикой онкологических заболеваний? Это очень важное и интересное направление, поскольку мы научились визуализировать клетки в физиологических условиях, наблюдать морфологию, рост клеток, можем отличать активные формы раковых клеток от неактивных. Более того, используя многоканальную капиллярную микроскопию, мы можем воздействовать на клетки реагентами и медицинскими препаратами, изучая при этом их ответную реакцию. Капиллярная микроскопия позволяет изучить морфологию клеток, в том числе и в случае развитых поверхностей без типичного для атомносиловой микроскопии эффекта уширения, поскольку используются нанокапилляры существенно более острые, чем кантилеверы. Проблема, которой мы сейчас занимаемся, это увеличение скорости измерений. Задача создать скоростной сканирующий капиллярный зондовый микроскоп, работающий на частоте 1 МГц с кадровой частотой не менее 30 кадров в секунду. В перспективе для исследования образцов биологических тканей планируется переход электроники на гигагерцовые частоты. Это позволит проводить диагностику масштабных массивов клеток, решать сложные вопросы в онкологии.

Сможет ли оборудование, которое вы разрабатываете, быть использовано в хирургии, позволит ли когда-нибудь перейти от уже ставшей привычной микрохирургии к нанохирургин?

Теоретически это возможно. Мы сейчас ведем поиск партнеров, с которыми могли бы начать цикл новых исследований в этом направлении. Одним из них может оказаться Российский национальный исследовательский медицинский университет имени Н.И.Пирогова. Совместно с заведующим кафедрой госпитальной хирургии С.Г.Шаповальянцем мы пробуем решить задачу прохождения катетера через проблемные зоны, например, протоки желчного пузыря или поджелудочной железы. При воспалении этих органов прохождение катетера затруднено, поэтому нами была предложена конструкция, в которой кончик катетера вибрирует с переменной частотой и амплитудой. Эта задача близка к тематике атомно-силовой микроскопии, в которой зонд деликатно ощупывает рельеф поверхности. Остается изготовить действующий прототип и провести клинические испытания прибора.

Если уж мы заговорили о партнерах, расскажите, пожалуйста, работа с какими партнерами вам представляется наиболее успешной и с кем вы работаете сейчас?

Юрий Львович Любченко из медицинского центра в Небраске - наш давний партнер и коллега. Он уже около 30 лет возглавляет группу исследователей США, занимается изучением 
молекулярных основ таких заболеваний, как болезнь Альцгеймера и Паркинсона. В работе они активно используют программное обеспечение "ФемтоСкан Онлайн" для анализа и обработки данных. Подсчет числа молекул белков и днк, оценка характера их взаимодействия, анализ движения ДНК - все эти серьезные операции по анализу данных проводятся автоматическим образом.

Полезным и нужным является сотрудничество с Институтом растений (Scottish Crop Research Institute, Шотландия), где изучают возможности использования вирусов для технологически полезных целей. Например, в присутствии вирусных частиц можно без добавления химических реагентов синтезировать наночастицы металлов, например, золота. Это переход к "зеленой химии" и биосенсорике нового типа (наночастицы золота применяются, например, в тестах на беременность). Вирусоподобные частицы при удалении РНК превращаются в оболочки, которые можно заполнять по своему усмотрению. Их можно использовать как центры кристаллизации, как материалы для конструкций и клеточных матриц (скаффолдов) в биопечати. В результате сотрудничества у нас вышла совместная научная статья, которую за несколько лет процитировали более 500 раз.

Очень поучительными были и наши контакты с LG Electronics. В своих исследовательских центрах они используют такое же оборудование, как и в МГУ, но их неоспоримым преимуществом является наличие производственной базы, позволяющей оперативно превращать возникшую идею в готовое изделие. Поэтому мы очень рады планам МГУ по созданию инновационного научно-технологического центра "Воробьевы горы". В далеком 1996 году мы создали первый полнофункциональный микроскоп "ФемтоСкан" с возможностью управления через Интернет, что было на тот момент прорывом в области приборной базы микроскопии. Нечто подобное, только в бо́льших объемах, мы ожидаем и от нашего возможного участия в работе научно-технологического центра МГу "Воробьевы горы". Создаваемое оборудование должно быть интерактивным и использоваться в таких центрах не только в научных, но и в образовательных целях, давать студентам возможность проводить свои исследования еще на этапе обучения в вузе.
Мы все время говорим о достижениях и разработках, пора перейти и к разбору недостатков, что, по вашему мнению, является тормозом научных исследований, сдерживающими факторами неизбежного научного и технологического прорыва, что нас удаляет от него?

Факторов торможения достаточно, но и пути их преодоления, к счастью, есть. К примеру, закупки необходимых зарубежных расходных материалов и комплектующих происходят сложно и медленно, требуют бумажного оформления для прохождения процедур бюрократической машины. По нашему мнению, для исследовательских институтов надо упростить закупку, что значительно сократит время на разработку инновационных высокотехнологических продуктов. Как это сделать? В эпоху цифровой экономики все то, что было приобретено, прошло таможню и поставлено на бухгалтерский учет в организации, можно легко отследить без вороха разрешительных документов. При этом организация может уплатить все положенные таможенные сборы, налоги и прочие отчисления уже после приобретения необходимых комплектующих. Это важнейший вопрос доверия. А доверять и помогать ученым надо. Хорошим примером доверия является работа Российского фонда фундаментальных исследований, где финансирование полностью выделяется под научного руководителя, возлагая на него бремя ответственности за расходование средств. Взамен ученому предлагается значительная свобода действий, в том числе в области финансов. Эффективно работает и Фонд содействиям инновациям благодаря полностью электронной системе контроля исполнения проектов.

Насущной проблемой является существующая система подачи заявок на поддержку научных и прикладных исследований. Ее необходимо менять, упрощать и унифицировать. Требуется единый стандарт в оформлении заявок, от списка необходимых документов до правил оформления литературы. Необходима система "единого окна" для всех научных конкурсов, аналог МФЦ (Многофункционального центра "Мои документы"). В целом стоит признать существующий прогресс в области финансирования проектов, совершенствования правил получения грантовой поддержки и подготовки 
отчетов. Создаются эффективные и удобные базы данных достижений ученых, например, система "Истина" в МГУ. В результате ученый имеет свою электронную страничку со всеми достижениями, тезисами, статьями. Одним из показателей эффективности ученого становится качество его публикаций. И здесь за качество борются и сам автор публикации, и само издание. Одним из таких изданий, в нашей области, безусловно, является и ваш журнал. Таких успешных журналов должно становиться больше. Цифровизация жизни подталкивает к идее создания электронного двойника человека, содержащего все необходимые сведения для прохождения бюрократических процедур. Это значительно сократило бы существующий документооборот и сделало бы жизнь полноценнее.

Получилось так, что наша компания "Центр перспективных технологий" стала долгожи" тельницей среди мировых компаний, работающих в области сканирующей зондовой микроскопии. С момента основания компании, 12 сентября 1990 года, мы всегда делали сами все необходимое - от механики, электроники и до программного обеспечения - всегда качественно и в срок. В этом ключевой секрет долгожительства компании. Мы всегда выбирали самые простые в исполнении решения, которые, оказывались и самыми эффективными. В результате, например, был создан микроскоп "ФемтоСкан", который может работать в шумных условиях без дополнительных развязок, антивибрационных столов, защитных экранов и пр.

В каких направлениях нужно двигаться отечественным производителям, чтобы помочь в вашей работе?

Разработка отечественных операционных систем с открытым кодом ускорит все этапы разработки открытого программного обеспечения для нашего оборудования. Очень неудобно работать с операционными системами с закрытым кодом, когда приходится действовать путем проб и ошибок. И, главное, нет полной гарантии безукоризненной работы конечного результата из-за неучтенных особенностей закрытых систем.

Второе направление, которое хотелось бы выделить - создание отечественной микроэлектронной базы комплектующих. Начиная с микроскопа "Скан-8" и до нашей последней разработки "ФемтоСкан X", мы всегда выбирали самые лучшие имеющиеся зарубежные электронные компоненты (операционные усилители, сигнальные процессоры и другие компоненты), при этом их доля в общей стоимости микроскопа не превышала 5-10\%. Сдерживает не вопрос цены, а проблема доступности элементной базы, быстрого приобретения электронных комплектующих.

Зарубежный рынок электроники постоянно меняется, нужные комплектующие перестают выпускаться, под новые компоненты приходится переписывать алгоритмы управления в ПО. Наличие отечественного, хорошо документированного комплекса микроэлектроники с собственной архитектурой для выбора необходимых опций резко сократило бы время поиска элементной базы.

Третья составляющая успешной работы это стабильное развитие точной отечествен ${ }^{-}$ ной механообработки в совокупности с совершенствованием стандартов оформления конструкторской документации. Нужно пересмотреть и отказаться от ряда ГОСТов, поскольку во многом они уже морально устарели. Мир уже живет в новом технологическом укладе, современные цифровые станки давно работают с цифровыми моделями, а не с чертежами. Для малых и средних предприятий оформление всех разработок, изделий и продукции согласно требованиям ГОсТов, созданных в парадигме предыдущего технологического уклада, - это тяжелое и не нужное испытание, идущее вразрез с инновационными перспективами.

\section{Что бы вы хотели пожелать нашим читате-} лям?

Свободный труд и творчество наиболее эффективны при отсутствии тотального контроля и в атмосфере максимального доверия. Отчетность должна следовать за творческим поиском, а не становиться непреодолимой стеной перед ученым. Борьба с дремучим охранительством и бюрократической мертвечиной уже идет. Лучше посвятить больше времени общению ученых друг с другом, с молодежью, со специалистами из смежных и далеких областей. Только в этом случае возможен прорыв научной и технологической мысли.

Большое спасибо за интересную беседу. С И.В.Яминским беседовал А.Н.Алёшин 